\title{
Quantifying the real-world cost saving from using surgical adjuncts to prevent complications during cataract surgery
}

\author{
Aaron Jamison $\mathbb{D}^{1} \cdot$ Larry Benjamin ${ }^{2} \cdot$ David Lockington $^{1}$
}

Received: 9 March 2018 / Revised: 28 April 2018 / Accepted: 16 May 2018 / Published online: 6 June 2018

(c) The Royal College of Ophthalmologists 2018

\begin{abstract}
Introduction Surgical adjuncts in cataract surgery are often perceived as sometimes necessary, always expensive, particularly in the "lean" cost-saving era. However, prevention of a surgical complication, rather than subsequent management, should always be the preferred strategy. We wished to model real-world costs associated with surgical adjuncts use and test the maxim for cataract surgery- "if you think of it, use it".

Methods We compared UK list prices for equipment and related costs of preventing vitreous loss (VL) via use of surgical adjuncts vs its subsequent management in a hypothetical cataract surgery scenario of a white swollen cataract with a moderately dilated pupil.

Results The original surgery costs for the "cautious with adjuncts, no complications" approach was $£ 943.54$, including adjuncts costing £137.47. In the "minimalist, no adjunct" scenario, management of VL using the Anterior Vitrectomy Kit cost $£ 142.45$, and additional management and follow-up costs resulted in total cost of $£ 1178.20$ ( $£ 234.66(25 \%)$ more expensive). If left aphakic, an additional operation for secondary iris clip IOL insertion and further follow-up to address the impact of the complication ultimately cost $£ 2124.67$ overall. An additional initial spend on surgical adjuncts of $£ 137.47$ could potentially prevent $£ 1293.60$ ( $9 \times$ increase) in direct costs in this scenario.

Conclusions Through simple scenario modelling, we have demonstrated the cost benefits provided by the use of precautionary surgical adjuncts during cataract surgery. VL costs significantly more in terms of complication management and follow-up. This supports the cataract surgeon's maxim- "if you think of it, use it".
\end{abstract}

\section{Introduction}

Cataract surgery is one of the most successful elective surgical operations undertaken in the NHS. The RCOphth National Ophthalmology Database study of cataract surgery reported that $50.8 \%$ of patients achieved postoperative bestcorrected visual acuity of " $0.00 \log$ MAR or better", and $94.6 \%$ achieved "0.30 logMAR or better" [1, 2]. Cataract surgery has also been demonstrated to be beneficial and cost-effective in patients with a guarded prognosis, including vision-limiting conditions, such as advanced glaucoma

David Lockington

davidlockington@hotmail.com

1 Tennent Institute of Ophthalmology, Gartnavel General Hospital, 1053 Great Western Road, Glasgow G12 0YN, UK

2 Department of Ophthalmology, Stoke Mandeville Hospital, Aylesbury HP21 8AL, UK or age-related macular degeneration [3, 4]. There is a small, but significant, risk of visually significant complications following cataract surgery-endophthalmitis, retinal detachment and cystoid macular oedema (CMO) $[1,5,6]$. The incidence of these conditions increases in the setting of intra-operative posterior capsular rupture (PCR) and vitreous loss (VL), surgical complications which can lead to endophthalmitis (eight times more likely_odds ratio [OR] =7.94), retinal detachment $(\mathrm{OR}=41.66)$ and $\mathrm{CMO}$ (relative risk $[R R]=2.61)[1,6,7]$. It follows that optimal management of an intra-operative complication is of paramount importance to the eventual visual outcome. For example, Osher's group reported that $48 \%$ of anterior capsule tears extend around the equator through the posterior capsule, and $19 \%$ require a vitrectomy [8].

In light of this, many authors have recommended the use of prior simulation to guide the surgeon in these rare but predictable surgical scenarios, through low-cost surveys of trainee experience, wet and dry laboratory facilities and computer simulation [9-17]. Ease of access to a pre- 
prepared Anterior Vitrectomy Kit with associated adjuncts (AntVitKit) to help with the prompt and appropriate management of VL has been previously described [18].

At the recent UKISCRS annual meeting's Plenary Symposium regarding "How to manage Vitreous Loss" in September 2017, concern was raised during a period of open discussion from a member of the audience regarding the cost of simulating such clinical scenarios on a recurrent basis for both trainees and staff [18]. The panel's response correctly focussed on the greater cost of not carrying out regular simulation training, resulting in sub-optimal management of rare events and the potential for further complications [19]. Prevention of a surgical complication, rather than subsequent management, should always be the preferred strategy. However, we acknowledge the reality that often such strategies have not been clearly quantified. Surgical adjuncts are often perceived to be expensive, particularly in the modern cost-saving era of "lean surgical practices". In light of this, we wished to model a common clinical cataract surgery scenario to illustrate the finances involved and test the following frequently used maxim: when considering surgical adjuncts during cataract surgery training, and beyond- "if you think of it, use it".

All ophthalmic surgeons will have encountered the internal debate at the start of a cataract operation where they have been faced with a sub-optimal pupil or reduced red reflex and found themselves considering the impact, utility or need of using additional surgical adjuncts such as mechanical iris dilation devices, capsular staining with trypan blue dye or intracameral agents [20]. But what bearing should cost have on such a decision, and what is the true cost of the alternative?

\section{Methods}

We considered the direct medical costs associated with a specific intra-operative cataract scenario (a white swollen cataract with a moderately dilated pupil) and estimated the cost of using additional surgical adjuncts to avoid a complication (cautious/safe surgery-scenario A). We compared this to the cost and the subsequent impact of experiencing the complication of PCR/VL in the setting of not initially using surgical adjuncts (minimalistic approach - scenarios B and C, see below).

The preferred practice of the senior authors has been used for illustrative purposes and includes the ready-to-use AntVitKit (a prefilled bag containing an anterior vitrector, triamcinolone, acetylcholine and a 10-0 nylon suture) described previously for use in combination with a regular "vitreous loss fire drill" [18]. To avoid issues of commercial sensitivities and potential cost variability between ophthalmology departments, cited costs are the UK product list prices (including 20\% VAT), obtained directly from each manufacturer in April

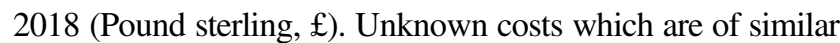
magnitude in both scenarios are mentioned but can be ignored for the purposes of this article, as the primary commentary will focus on the proportional difference in costs.

\section{Scenario A: Complex cataract surgery, additional adjuncts used, but no complications}

A "cautious" approach to a white swollen cataract and moderately dilated pupil, including the use of an iris expansion ring device, trypan blue capsular staining and denser cohesive viscoelastic, results in complex but uncomplicated surgery. Routine postoperative follow-up was deferred to community optometry.

\section{Scenario B: Complicated cataract surgery, no adjuncts used initially, VL encountered, sulcus lens inserted during primary procedure}

A "minimalist" approach to a similar cataract scenario, with no preventative surgical adjuncts used, resulted in PCR and VL. No nuclear fragments were lost posteriorly. Following an anterior vitrectomy, there was sufficient capsular support to place a three-piece lens in the sulcus. This patient requires follow-up in the clinic at day 1 and 1 month postoperatively.

\section{Scenario C: Complicated cataract surgery, no adjuncts used initially, VL encountered, no capsule support, left aphakic, iris clip lens inserted as a secondary procedure}

The same "minimalist" approach resulted in PCR and VL with no nuclear fragments lost posteriorly. Following an anterior vitrectomy, there was insufficient capsular support and the patient was left aphakic. This patient will be reviewed in the clinic at day 1 and secondary iris clip IOL insertion will be planned. They will require a further surgical procedure and will have to attend at least one additional clinic visit following each procedure.

\section{Results}

Tables 1 and 2 outline the direct medical costs estimated to arise in each scenario. For simplicity, we assumed that there were no additional associated complications other than what has been modelled in these scenarios.

\section{Original surgery costs}

The original surgery costs for the "cautious approach" scenario A was $£ 943.54$. This included an additional initial spend of $£ 137.47$ on surgical adjuncts. 
Table 1 Table modelling direct medical costs, using UK list prices, associated with using surgical adjuncts for complication prevention in cataract surgery (scenario A) compared with the costs associated with the management of vitreous loss and use of threepiece sulcus IOL (scenario B)

\begin{tabular}{|c|c|c|c|c|}
\hline \multirow[b]{2}{*}{ Initial set-up } & \multicolumn{2}{|c|}{$\begin{array}{l}\text { Scenario A: "Cautious" approach } \\
\text { with adjuncts }\end{array}$} & \multicolumn{2}{|c|}{$\begin{array}{l}\text { Scenario B: "Minimalist" approach } \\
\text { without adjuncts (sulcus lens during } \\
1^{\circ} \text { procedure) }\end{array}$} \\
\hline & Basic "phaco" set-up" a & $£ 666.57$ & Basic "phaco" set-up a & $£ 666.57$ \\
\hline \multirow[t]{5}{*}{ Surgical adjuncts } & $\begin{array}{l}1.4 \% \text { sodium hyaluronate } \\
\text { OVD }\end{array}$ & $£ 27.00$ & $\begin{array}{l}1 \% \text { sodium hyaluronate } \\
\text { OVD }\end{array}$ & $£ 25.00$ \\
\hline & Iris expansion ring device & $£ 99.00$ & & \\
\hline & Trypan blue capsular stain & $£ 11.47$ & & \\
\hline & Subtotal & $£ 137.47$ & Subtotal & $£ 25.00$ \\
\hline & \multicolumn{4}{|c|}{ "A" is $£ 112.47$ more expensive } \\
\hline \multirow[t]{9}{*}{ Rest of surgery } & \multirow[t]{5}{*}{ 1-piece monofocal lens } & \multirow[t]{5}{*}{$£ 132.00$} & Anterior vitrector $^{\mathrm{b}}$ & $£ 120.00$ \\
\hline & & & $40 \mathrm{mg} / \mathrm{ml}$ triamcinolone ${ }^{\mathrm{b}}$ & $£ 1.66$ \\
\hline & & & $\begin{array}{l}\text { Acetylcholine chloride } \\
\text { solution }^{\mathrm{b}}\end{array}$ & $£ 8.39$ \\
\hline & & & $10 / 0$ nylon suture ${ }^{\mathrm{b}}$ & $£ 12.40$ \\
\hline & & & $\begin{array}{l}\text { 3-piece monofocal sulcus } \\
\text { lens }\end{array}$ & $£ 65.00$ \\
\hline & Intracameral cefuroxime & $£ 5.22$ & Intracameral cefuroxime & $£ 5.22$ \\
\hline & Postoperative drops & $£ 2.28$ & Postoperative drops ( $\uparrow$ ed) & $£ 3.96$ \\
\hline & Subtotal & $£ 139.50$ & Subtotal & $£ 216.63$ \\
\hline & \multicolumn{4}{|l|}{ " $\mathrm{B}$ " is $£ 77.13$ more expensive } \\
\hline \multirow[t]{3}{*}{ Day 1 postoperative review } & Not required & N/A & $\begin{array}{l}\text { Additional clinic } \\
\text { appointment \#1 }\end{array}$ & $£ 135.00$ \\
\hline & Subtotal & $£ 0$ & Subtotal & $£ 135.00$ \\
\hline & \multicolumn{4}{|c|}{ " $\mathrm{B}$ " is $£ 135.00$ more expensive } \\
\hline \multirow[t]{3}{*}{ Month 1 postoperative review } & $\begin{array}{l}\text { Community optometrist } \\
\text { review }\end{array}$ & N/A & $\begin{array}{l}\text { Additional clinic } \\
\text { appointment \#2 }\end{array}$ & $£ 135.00$ \\
\hline & Subtotal & $£ 0$ & Subtotal & $£ 135.00$ \\
\hline & \multicolumn{4}{|c|}{ " $\mathrm{B}$ " is $£ 135.00$ more expensive } \\
\hline \multirow[t]{3}{*}{ Overall Costs } & Overall total & $£ 943.54$ & Overall total & $£ 1178.20$ \\
\hline & \multicolumn{4}{|c|}{ " $\mathrm{B}$ " is $£ 234.46$ more expensive } \\
\hline & \multicolumn{4}{|c|}{ (Proportional difference $=" \mathrm{~A} "$ is $19.9 \%$ less expensive) } \\
\hline
\end{tabular}

${ }^{a}$ For this illustration, a basic "phaco" set-up includes $1 \times$ set of gloves (£2.19), $1 \times$ sterile gown (£1.09), povidone iodine $(\sim £ 1.31), 1 \times$ sterilized basic tray $(£ 7.20), 1 \times 1 \%$ lidocaine vial $(£ 0.24), 1 \times$ keratome (£9.00), $1 \times$ disposable chopper (£17.64), $1 \times$ set of rhexis forceps $(£ 14.75), 1 \times$ bimanual I/A $(£ 13.50), 1 \times$ phaco pack ( $£ 64.23$, includes phaco drape), plus cost of one theatre slot $(£ 535.42=£ 150.27$ staffing costs and $£ 385.15$ indirect/"overhead" costs)

bThe Anterior Vitrectomy Kit or "AntVitKit" (£142.45)
The cost of managing VL using the Anterior Vitrectomy Kit was $£ 142.45$ resulting in the original surgery costs for the "minimalistic approach, no adjuncts, VL, sulcus IOL" scenario B of $£ 908.20$ and the original surgery costs for the "minimalistic approach, no adjuncts, VL, left aphakic" scenario $\mathrm{C}$ of $£ 843.20$.

\section{Follow-up and future management costs}

As there was no requirement for further follow-up in scenario A, future management costs with the "cautious but uncomplicated" approach were $£ 0$.
The additional costs due to further follow-up and intervention to address the impact of the complication in the "minimalistic approach" were $£ 347.13$ if a sulcus lens was implanted during the primary procedure (scenario B) and $£ 1293.60$ if an iris clip lens was inserted as a secondary procedure (scenario $\mathrm{C}$ ). In scenario $\mathrm{C}$, the minimum physical impact for the patient would be a loss of 3 working days due to one further surgical procedure and two additional clinic appointments (as a minimum) and the visual inconvenience/impact of monocular aphakia for the period of time between the two procedures. 
Table 2 Table modelling direct medical costs, using UK list prices, associated with using surgical adjuncts for complication prevention in cataract surgery (scenario A) compared with the costs associated with the management of vitreous loss, and a further secondary procedure to insert an iris clip IOL (scenario C)

\begin{tabular}{|c|c|c|c|c|}
\hline \multirow[b]{2}{*}{ Initial set-up } & \multicolumn{2}{|c|}{$\begin{array}{l}\text { Scenario A: "Cautious" approach with } \\
\text { adjuncts }\end{array}$} & \multicolumn{2}{|c|}{$\begin{array}{l}\text { Scenario C: "Minimalist" approach without } \\
\text { adjuncts (iris clip lens as } 2^{\circ} \text { procedure) }\end{array}$} \\
\hline & Basic "phaco" set-up" & $£ 666.57$ & Basic "phaco" set-up" & $£ 666.57$ \\
\hline \multirow[t]{5}{*}{ Surgical adjuncts } & $\begin{array}{l}1.4 \% \text { sodium hyaluronate } \\
\text { OVD }\end{array}$ & $£ 27.00$ & $\begin{array}{l}1 \% \text { sodium hyaluronate } \\
\text { OVD }\end{array}$ & $£ 25.00$ \\
\hline & Iris expansion ring device & $£ 99.00$ & & \\
\hline & Trypan blue capsular stain & $£ 11.47$ & & \\
\hline & Subtotal & $£ 137.47$ & Subtotal & $£ 25.00$ \\
\hline & "A" is $£ 112.47$ more expe & & & \\
\hline \multirow[t]{10}{*}{ Rest of surgery } & 1-piece monofocal lens & $£ 132.00$ & Anterior vitrector ${ }^{\mathrm{b}}$ & $£ 120.00$ \\
\hline & & & $40 \mathrm{mg} / \mathrm{ml}$ triamcinolone $\mathrm{e}^{\mathrm{b}}$ & $£ 1.66$ \\
\hline & & & $\begin{array}{l}\text { Acetylcholine chloride } \\
\text { solution }^{\mathrm{b}}\end{array}$ & $£ 8.39$ \\
\hline & & & $10 / 0$ nylon suture ${ }^{\mathrm{b}}$ & $£ 12.40$ \\
\hline & Intracameral cefuroxime & $£ 5.22$ & Intracameral cefuroxime & $£ 5.22$ \\
\hline & Postoperative drops & $£ 2.28$ & Postoperative drops ( $\uparrow$ ed) & $£ 3.96$ \\
\hline & Subtotal & $£ 139.50$ & Subtotal & $£ 151.63$ \\
\hline & "C" is $£ 19.13$ more expen & & & \\
\hline & Sub-total & $£ 943.54$ & Sub-total & $£ 843.20$ \\
\hline & & & NB: aphakic; no IOL cost & \\
\hline \multirow[t]{3}{*}{ First postoperative review } & $\begin{array}{l}\text { Community optometrist } \\
\text { review }\end{array}$ & N/A & $\begin{array}{l}\text { Additional clinic } \\
\text { appointment \#1 }\end{array}$ & $£ 135.00$ \\
\hline & Subtotal & $£ 0$ & Subtotal & $£ 135.00$ \\
\hline & "C" is $£ 135.00$ more expe & & & \\
\hline \multirow[t]{8}{*}{$2^{\circ}$ surgery } & Not required & N/A & Basic "phaco" set-up" & $£ 666.57$ \\
\hline & & & $\begin{array}{l}1 \% \text { sodium hyaluronate } \\
\text { OVD }\end{array}$ & $£ 25.00$ \\
\hline & & & Aphakia iris clip lens & $£ 300.00$ \\
\hline & & & $10 / 0$ nylon suture & $£ 12.40$ \\
\hline & & & Intracameral cefuroxime & $£ 5.22$ \\
\hline & & & Postoperative drops & $£ 2.28$ \\
\hline & Subtotal & $£ 0$ & Subtotal & $£ 1011.47$ \\
\hline & "C" is $£ 1011.47$ more exp & & & \\
\hline \multirow[t]{3}{*}{ Second postoperative review } & Not required & N/A & $\begin{array}{l}\text { Additional clinic } \\
\text { appointment \#2 }\end{array}$ & $£ 135.00$ \\
\hline & Subtotal & $£ 0$ & Subtotal & $£ 135.00$ \\
\hline & "C" is $£ 135.00$ more less & & & \\
\hline \multirow[t]{3}{*}{ Overall Costs } & Overall Total & $£ 943.54$ & Overall total & $£ 2124.67$ \\
\hline & "C" is $£ 1181.13$ more exp & & & \\
\hline & (Proportional difference $={ }^{\circ}$ & $6 \%$ less e & & \\
\hline
\end{tabular}

${ }^{a}$ For this illustration, a basic "phaco" set-up includes $1 \times$ set of gloves (£2.19), $1 \times$ sterile gown (£1.09), povidone iodine ( £1.31), 1× sterilized basic tray $(£ 7.20), 1 \times 1 \%$ lidocaine vial $(£ 0.24), 1 \times$ keratome $(£ 9.00), 1 \times$ disposable chopper $(£ 17.64), 1 \times$ set of rhexis forceps $(£ 14.75), 1 \times$ bimanual I/A (£13.50), $1 \times$ phaco pack ( $£ 64.23$, includes phaco drape), plus cost of one theatre slot $(£ 535.42=£ 150.27$ staffing costs and $£ 385.15$ indirect/"overhead" costs)

${ }^{\mathrm{b}}$ The Anterior Vitrectomy Kit or “AntVitKit” (£142.45)

\section{Overall costs}

The total overall cost of the "cautious approach" scenario A, with complications avoided, was $£ 943.54$. This was 55.6\% less than that of the "minimalist approach" scenario C, with which a complication was encountered and an iris clip lens was later inserted (£2124.67), and 19.9\% less than that of "minimalist approach" scenario B in which the same 
complication was encountered and a sulcus lens was implanted during the primary procedure (£1178.20).

When the above calculations were performed using the prices actually paid by NHS Greater Glasgow \& Clyde in April 2018 (i.e. personal communication of local contract prices), rather than the list prices, the total overall cost of scenario A was $24.1 \%$ less than for scenario B and $56.7 \%$ less than for scenario $\mathrm{C}$.

To summarize, an additional initial spend of $£ 137.47$ on surgical adjuncts (scenario A) could potentially prevent $£ 347.13$ (2.5 times) or $£ 1293.60$ (9.4 times) further direct costs identified with the management of the surgical complication of $\mathrm{VL}$ encountered in scenarios $\mathrm{B}$ or $\mathrm{C}$, respectively.

\section{Discussion}

The current published literature discussing the costs of modern cataract surgery understandably focus on technological advancements [21]. These include the delivery of ultrasound energy (femto vs phaco), type of operation (phaco vs small incision extracapsular cataract extraction) and devices to create a reproducible circular anterior capsulorrhexis (laser vs zepto vs other) [21-24]. There is a relative paucity of specific information in the literature regarding the cost of a complication. Such publications tend to arise from countries with electronic billing systems, where large data sources can be trawled for trends.

Schmier et al. used United States Medicare Limited Data Sets to identify patients who had developed a specific complication (postoperative $\mathrm{CMO}$; postoperative endophthalmitis) following cataract surgery and those who did not ("controls") [25-28]. By considering the total reimbursements paid, they identified the increased cost of managing these complicated cases in both instances. In the case of CMO, this was an $85 \%$ increase vs "control" (\$2720 vs $\$ 1470$ ), and in the case of endophthalmitis, a $78 \%$ increase $(\$ 11,551$ vs $\$ 6488)[27,28]$. In these examples, the additional increased cost of complication-related CMO and endophthalmitis have been estimated in the USA system to be in the region of $\$ 1250$ and $\$ 5000$, respectively. This real-world analysis cannot, however, provide more specific details regarding which, if any, precautionary measures were adopted in each case.

Through our worked example, we have highlighted the potential financial benefits provided by the appropriate use of surgical adjuncts during cataract surgery. There are some clear principles to be gleaned from identifying the true costs of surgical behaviour. The first misconception is a commonly held belief that using surgical adjuncts are expensive, an unhelpful statement when made without context. In the setting of complex surgery, it is more cost-effective to prevent a complication, rather than having to manage it. We have shown that the initial additional spend of $£ 137.47$ on appropriate surgical adjuncts has, in the "cautious" scenario A, prevented $£ 347.13$ and $£ 1293.60$ in further costs identified with the management of the surgical complication of VL encountered in scenarios B and C, respectively. Moreover, once the surgeon has had to open the Anterior Vitrectomy Kit at a cost of $£ 142.45$, any initial cost saving from not using surgical adjuncts has evaporated. This reinforces the importance of forward planning prior to surgery.

The second principle to note is that surgical complications are ultimately much more expensive, both in the initial and future management. These costs are not always clearly stated nor are they always acknowledged, as they often come from different budgets (theatre costs administrated separately from outpatient follow-up). Hence, we have tried to demonstrate the true costs associated with safe surgery vs complicated surgery. We have outlined just two "complicated scenarios", but the costs incurred would be greatly increased if, for example, the hypothetical patient suffered a dropped nucleus, requiring vitreo-retinal input, or had further significant postoperative complications, such as CMO, retinal detachment or endophthalmitis.

In this paper, we have not itemized the carbon footprint associated with each of our three scenarios, but it could be expected to be significantly greater in the case of a surgical complication. The carbon footprint of cataract surgery is currently a topic of much debate, and while it can be correctly used as a driver to reduce unnecessary waste, it can inadvertently result in a lack of effective (often disposable) equipment being available for the surgeon [29-32]. Any drive to "lean" working practices should not result in such lowstock equipment levels that the patient's surgical management, and subsequent outcomes, could be jeopardized and have medico-legal implications. This may be of increasing relevance, as a recent 15-year report on 963 clinical negligent cases in ophthalmology reported the cataract subspecialty as having the highest number of claims (34\%) [33].

Our comparison also does not consider the financial impact of potentially long-term visual impairment, as described by Frick et al. (including increased expenditure on other medical care, non-medical expenditures such as aids and adaptations, increased travel costs and loss of productivity, both for the patient and potentially their relatives) [34-36]. It also cannot consider, finances aside, the amount of anxiety experienced by the patient, the potential impact on their quality of life or the effect that potential visual impairment could have on the patient's family, caregivers and the community. In this instance, Getting It (the surgery) Right First Time has a huge impact on both patient and the hospital. "Getting It Right First Time" (GIRFT) is a recent orthopaedic-based report that addressed 
unnecessary variations in pathways of care, patient experiences and surgical outcomes. These concepts are currently being applied to other sub-specialties (including ophthalmology) [37]. We acknowledge that our basic modelling is limited, as sometimes the minimalist approach will be uneventful, and on other occasions using surgical adjuncts will not prevent complications, but their appropriate utilization should reduce the frequency of VL (in conjunction with risk stratification and appropriate case selection) [5]. In line with the GIRFT principles, it is our belief that the availability and use of surgical adjuncts may be a clear instance where "spending a little can save a lot more" in future costs.

\section{Conclusion}

Through basic modelling of potential outcomes from the surgical approach to a white cataract with moderate pupil dilation, we have demonstrated the real-world cost benefits associated with the use of precautionary surgical adjuncts in prevention vs management of the common complication of PCR/VL in cataract surgery. Without published data reporting the RR reduction in the incidence of PCR offered by use of individual surgical adjuncts, it is not possible to perform a specific cost-effectiveness analysis. Despite this, we believe that this article has addressed and quantified some of the issues influencing surgical decision making and additional equipment use. VL costs significantly more in terms of complication management and follow-up, both to the ophthalmology department and, much more importantly, the patient. We have also provided an evidence base to support the maxim for the operating surgeon with regards to surgical adjuncts- -if you think of it, use it".

\section{Summary}

\section{What was known before}

- Surgical adjuncts in cataract surgery are often perceived as sometimes necessary, but always expensive, particularly in the lean cost-saving era.

- Prevention of a surgical complication, rather than subsequent management, should always be the preferred strategy.

- Trainee surgeons are often taught the maxim regarding surgical adjuncts in cataract surgery-if you think of it, use it.

\section{What this study adds}

- An additional initial spend on surgical adjuncts of $£ 137.47$ could potentially prevent $£ 1293.60$ (9x) in direct costs from management of vitreous loss.

- The cost of using the Anterior Vitrectomy Kit was $£ 142.45$, so negating any potential saving from not initially using surgical adjuncts.

- This article has quantified some of the costs influencing surgical decision making and additional equipment use, demonstrating that it is cheaper to prevent, rather than manage, a complication.

- We have provided an evidence base to support the maxim for the operating surgeon with regards to surgical adjuncts-if you think of it, use it.

\section{Compliance with ethical standards}

Conflict of interest The authors declare that they have no conflict of interest.

\section{References}

1. Day AC, Donachie PH, Sparrow JM, Johnston RL. Royal College of Ophthalmologists' National Ophthalmology Database. The Royal College of Ophthalmologists' National Ophthalmology Database study of cataract surgery: report 1 , visual outcomes and complications. Eye (Lond). 2015;29:552-60.

2. Lundström M, Barry P, Henry Y, Rosen P, Stenevi U. Visual outcome of cataract surgery; study from the European Registry of Quality Outcomes for Cataract and Refractive Surgery. J Cataract Refract Surg. 2013;39:673-9.

3. Ma Y, Huang J, Zhu B, Sun Q, Miao Y, Zou H. Cost-utility analyses of cataract surgery in advanced age-related macular degeneration. Optom Vis Sci. 2016;93:165-72.

4. Xu X, Ma YY, Zou HD. Cost-utility analysis of cataract surgery in advanced glaucoma patients. J Glaucoma. 2016;25: e657-62.

5. Narendran N, Jaycock P, Johnston RL, Taylor H, Adams M, Tole DM, et al. The Cataract National Dataset electronic multicentre audit of 55,567 operations: risk stratification for posterior capsule rupture and vitreous loss. Eye (Lond). 2009;23:31-7.

6. Day AC, Donachie PH, Sparrow JM, Johnston RL. Royal College of Ophthalmologists' National Ophthalmology Database. United Kingdom National Ophthalmology Database Study of Cataract Surgery: Report 3: pseudophakic retinal detachment. Ophthalmology. 2016;123:1711-5.

7. Chu CJ, Johnston RL, Buscombe C, Sallam AB, Mohamed Q, Yang YC. Risk factors and incidence of macular edema after cataract surgery: a database study of 81984 eyes. Ophthalmology. 2016;123:316-23.

8. Marques FF, Marques DM, Osher RH, Osher JM. Fate of anterior capsule tears during cataract surgery. J Cataract Refract Surg. 2006;32:1638-42.

9. McCannel CA. Continuous curvilinear capsulorhexis training and non-rhexis related vitreous loss: the specificity of virtual reality simulator surgical training (An American Ophthalmological Society Thesis). Trans Am Ophthalmol Soc. 2017; 115:T2.

10. Thomsen AS, Bach-Holm D, Kjærbo H, Højgaard-Olsen K, Subhi Y, Saleh GM, et al. Operating room performance improves after proficiency-based virtual reality cataract surgery training. Ophthalmology. 2017;124:524-31. 
11. Thomsen AS, Smith P, Subhi Y, Cour M, Tang L, Saleh GM, et al. High correlation between performance on a virtual-reality simulator and real-life cataract surgery. Acta Ophthalmol. 2017;95:307-11.

12. Nandigam K, Soh J, Gensheimer WG, Ghazi A, Khalifa YM. Cost analysis of objective resident cataract surgery assessments. J Cataract Refract Surg. 2015;41:997-1003.

13. Spiteri AV, Aggarwal R, Kersey TL, Sira M, Benjamin L, Darzi AW, et al. Development of a virtual reality training curriculum for phacoemulsification surgery. Eye (Lond). 2014;28:78-84.

14. Baxter JM, Lee R, Sharp JA, Foss AJ, Intensive Cataract Training Study Group. Intensive cataract training: a novel approach. Eye (Lond). 2013;27:742-6.

15. Turnbull AM, Lash SC. Confidence of ophthalmology specialist trainees in the management of posterior capsule rupture and vitreous loss. Eye (Lond). 2016;30:943-8.

16. Brogan K, Dawar B, Lockington D, Ramaesh K. Intraoperative head drift and eye movement: two under addressed challenges during cataract surgery. Eye (Lond). 2018. https://doi.org/10. 1038/s41433-018-0047-x.

17. McCannel CA, Reed DC, Goldman DR. Ophthalmic surgery simulator training improves resident performance of capsulorhexis in the operating room. Ophthalmology. 2013;120:2456-61.

18. Lockington D, Belin M, McGhee CNJ. The need for all cataract surgeons to run a regular vitreous loss fire drill. Eye. 2017;31:1120-1.

19. Lockington D, Flowers H, Young D, Yorston D. Ensuring accuracy of intravitreal antibiotics and the need for training. Br J Ophthalmol. 2009;93:1126.

20. Lockington D, Macdonald EC, Young D, Stewart P, Caslake M, Ramaesh K. Presence of free radicals in intracameral agents commonly used during cataract surgery. $\mathrm{Br} \mathrm{J}$ Ophthalmol. 2010;94:1674-7.

21. Chang DF. The continuing evolution of cataract surgery. Asia Pac J Ophthalmol (Phila). 2017;6:308.

22. Abell RG, Vote BJ. Cost-effectiveness of femtosecond laserassisted cataract surgery versus phacoemulsification cataract surgery. Ophthalmology. 2014;121:10-6.

23. Agarwal A, Kumar DA. Cost-effectiveness of cataract surgery. Curr Opin Ophthalmol. 2011;22:15-8.

24. Chang DF, Mamalis N, Werner L. Precision pulse capsulotomy: preclinical safety and performance of a new capsulotomy technology. Ophthalmology. 2016;123:255-64.
25. Schmier JK, Halpern MT, Covert DW, Matthews GP. Evaluation of costs for cystoid macular edema among patients after cataract surgery. Retina. 2007;27:621-8.

26. Schmier JK, Halpern MT, Covert DW, Lau EC, Robin AL. Evaluation of Medicare costs of endophthalmitis among patients after cataract surgery. Ophthalmology. 2007;114:1094-9.

27. Schmier JK, Covert DW, Hulme-Lowe CK, Mullins A, Mahlis EM. Treatment costs of cystoid macular edema among patients following cataract surgery. Clin Ophthalmol. 2016;10:477-83.

28. Schmier JK, Hulme-Lowe CK, Covert DW, Lau EC. An updated estimate of costs of endophthalmitis following cataract surgery among Medicare patients: 2010-2014. Clin Ophthalmol. 2016;10:2121-7.

29. Morris DS, Wright T, Somner JE, Connor A. The carbon footprint of cataract surgery. Eye (Lond). 2013;27:495-501.

30. Thiel CL, Schehlein E, Ravilla T, Ravindran RD, Robin AL, Saeedi OJ, et al. Cataract surgery and environmental sustainability: waste and lifecycle assessment of phacoemulsification at a private healthcare facility. J Cataract Refract Surg. 2017;43:1391-8.

31. Somner J, Scott K, Morris D, Gaskell A, Shepherd I. Ophthalmology carbon footprint: something to be considered? J Cataract Refract Surg. 2009;35:202-3.

32. Venkatesh R, van Landingham SW, Khodifad AM, Haripriya A, Thiel CL, Ramulu P, et al. Carbon footprint and cost-effectiveness of cataract surgery. Curr Opin Ophthalmol. 2016;27:82-8.

33. Mathew RG, Ferguson V, Hingorani M. Clinical negligence in ophthalmology: fifteen years of national health service litigation authority data. Ophthalmology. 2013;120:859-64.

34. Frick KD,Kymes SM,Lee PP,Matchar DB,Pezzullo ML,Rein DB, et al. Vancouver Economic Burden of Vision Loss Group. The cost of visual impairment: purposes, perspectives, and guidance. Invest Ophthalmol Vis Sci. 2010;51:1801-5.

35. Frick KD, Gower EW, Kempen JH, Wolff JL. Economic impact of visual impairment and blindness in the United States. Arch Ophthalmol. 2007;125:544-50.

36. Köberlein J, Beifus K, Schaffert C, Finger RP. The economic burden of visual impairment and blindness: a systematic review. BMJ Open. 2013;3:e03471.

37. MacEwen C, Davis A, Chang L. Getting it right first time for ophthalmology. Royal College of Ophthalmologists. 2017. https:// www.rcophth.ac.uk/2017/02/getting-it-right-first-time-for-ophthalmology/. Accessed 28 April 2018. 